\title{
Informal caring for back pain: Overlooked costs of back pain and projections to 2030.
}

Deborah Schofield $^{1}$, Melanie J B Zeppel ${ }^{1}$, Robert Tanton ${ }^{2}$, Jacob Veerman ${ }^{3}$, Simon Kelly ${ }^{2}$, Megan E Passey ${ }^{4}$, Rupendra N Shrestha ${ }^{1,5}$

${ }^{1}$ Centre for Economic Impacts of Genomic Medicine (GenIMPACT)

Department of Economics, Faculty of Business and Economics, Macquarie University, NSW 2109, Australia

${ }^{2}$ National Centre for Social and Economic Modelling,

University of Canberra, Bruce, ACT 2617, Australia

${ }^{3}$ School of Medicine

Griffith University, Gold Coast

Qld, Australia

${ }^{4}$ The University of Sydney, University Centre for Rural Health, Lismore, NSW 2480, Australia

${ }^{5}$ Corresponding Author

Running heading: Economic costs of caring for back pain, 2015-30

Word Count: 3294

Number of text pages: 19

Number of Figures and Tables: 2 figures and 3 tables.

Article Type: Basic Science Research

Summary:

- Informal caring for back pain was estimated to cost AU\$258m in lost income.

- Lost taxation was estimated to cost AU\$78 million, and welfare payments AU\$132 million. 
Key words: labour force participation; informal carers; back pain; lost productive life years; indirect costs; microsimulation models; dorsopathies

\begin{abstract}
:
This study models the economic costs of informal caring for people with back pain, using a microsimulation model, Care\&WorkMOD, from 2015 to 2030.

Care\&WorkMOD was based on three national Australian Surveys of Disability, Ageing and Carers (SDACs) $(2003,2009,2012)$ datasets for individuals aged 15 to 64 years old. Estimated national income loss due to caring for people with back pain was AU\$258 million in 2015, increasing to \$398 million in 2030 (54\% increase). Lost income tax revenue to the Australian government due to informal care of people with back pain was estimated to be AU\$78 million in 2015, increasing to AU\$118 million in 2030 (50\% increase), and additional welfare payments were estimated to rise from $\$ 132$ million in 2015 to AU\$180 in 2030 (36\% increase). Larger growth in lost income, compared to the increase in welfare payments, means that there would be an increasing income gap between those out of the labour-force providing informal care and non-carers who are in the labour-force, leading to increased inequality. Informal carers are defined as providers of informal, unpaid assistance to someone with a health condition, for at least six months. Informal carers of people with back pain who are out of the labour-force, incur substantial economic costs. Further, back pain is a large economic burden on National governments. Policies addressing back pain prevention and treatment, and supporting carers, may offset government welfare expenditure, while improving the socio-economic well-being of carers and patients.
\end{abstract}




\section{Introduction}

Low back pain is now the leading cause of disability worldwide [11]. Between 1990 to 2015 , the number of years lived with disability caused by back pain increased by $54 \%$, largely due to the ageing population [7; 11]. Global organisations such as the World Health Organisation have urged the importance of taking action to reduce the increasing effects of disabling low back pain [4]. Back pain is one of the most costly health conditions [16]. Some studies have quantified a range of societal costs of back pain, yet there is little research on economic costs of informal care for people with back pain in Australia [34]. Using national survey data, an Australian study that ranked chronic conditions informal carers provide care for, reported back problems $(12 \%)$ were the top condition, followed by arthritis (10\%) and nervous system diseases (7\%)[24].

Across the world many people stay out of the work force to provide informal care for people with chronic conditions $[17 ; 28 ; 32]$, impacting their capacity to generate income through work, leading to income loss. Staying out of the labour force not only reduces carers income, but also places an economic burden on the government through lost taxation revenue, and an increase in government welfare payments to those informal carers who stay out of the labour force. An Australian study recently estimated the economic cost of the lost labour force participation of informal carers to the government at \$2.44 billion in 2015 [28].

With an ageing population, both the number of people with back problems, and informal carers are likely rise in future. Thus, economic costs to both informal carers and the government are also likely to increase. Although a few studies have reported the economic burden of caring for back pain on informal carers [10;34], they quantified the impacts at a single time point. To our knowledge this is the first study in Australia and internationally to project economic costs of lost labour force participation of informal carers of care recipients with back pain over a long time-frame, from 2015 to 2030. This study aims to estimate the economic impacts for both informal carers, in terms of their lost income and for the government in terms of lost income tax revenue and increased welfare payments.

The novelty of this study is that (1) we model the costs of individuals matched for gender, age and education-level, reflecting the range of incomes across these variables, rather than using population average costs of hourly rates to determine lost productivity; 
(2) we estimate the national lost income tax and increased welfare, as well as lost income, and (3) project costs of informal care for persons with back pain into the future, to 2030 .

\section{Methods}

\section{Data}

We analysed the output datasets of an Australian microsimulation model, Care\&WorkMOD, designed to project the economic costs of lost productive life years of informal carers aged 15 to 64 years for every five years from 2015 to 2030 . A detailed description of model development is available in Shrestha et al [32]. Briefly, Care\&WorkMOD was based on unit-record data of individuals aged 15 to 64 years from the Australian Bureau of Statistics' (ABS) Surveys of Disability, Ageing and Carers (SDAC) 2003, 2009 and 2012 [1; 2; 27], with additional data from other Australian population representative datasets such as population and labour force projections from the 2015 Australian Intergenerational Report [8]; projected distributions of socio-demographic variables including the percentage of informal carers from the Australian Population and Policy Simulation Model (APPSIM) [15]; and output datasets from the Static Incomes Model (STINMOD) [19]. A schematic diagram of Care\&WorkMOD is provided in Figure 1.

The model uses static ageing to project the socio-demographic and economic profile of the Australian population to 2015, 2020, 2025 and 2030. Static ageing simulates the growth in the population over time through "reweighting". It is the process where the current population distribution such as the number of people by age group and sex are changed to match the projected population distribution by altering the weights of each record in the sample. Static ageing does not change the characteristics of individual record in the sample such as their labour force participation, informal caring status. It only changes the weights to reflect how many people there will be with these characteristics in the future. For a detailed description of model assumption and the parameters of Care\&WorkMOD, see Shrestha et al [32] and Schofield et al [28]. 
An informal carer is defined in the Surveys of Disability, Ageing and Carers (SDACs), and thus in Care\&WorkMOD, as a person who provides any informal assistance, in terms of help or supervision, to someone who has a disability or a long-term health condition, for at least six months, with no expectation of monetary compensation. This contrasts with formal carers who generally receive payment in return and provide these services as their primary occupation and are outside the scope of the SDACs. A primary informal carer is someone who provides the most informal assistance to a person with a disability with one or more of the core activities of mobility, self-care and communication. In the SDACs respondents were specifically asked if they were 'informal carers of people with a chronic condition', and for carers, a range of chronic health conditions their main care recipients had, and the main chronic health condition among them reported. The SDAC also questioned respondents about their labour force status, and if they were out of the labour force, the reason for this. Primary informal carers who reported being out of the labour force due to caring for "someone else's ill health or disability" and those who reported 'back pain or dorsopathies' as a main chronic condition of their main care recipient were considered an informal carer who was out of the labour force due to caring for 'backpain' in this analysis.

\section{Statistical analysis}

We estimated the mean, standard deviation and median of each of the weekly income, welfare payments, and taxes paid by people aged 15 to 64 years who were primary carers and out of the labour force due to their caregiving for people with back pain; and those who were non-carers and in the labour force (employed full-time, employed parttime). Costs were expressed in real 2015 Australian dollars.

The differences in economic costs for those not in the labour force (NILF) due to their caregiving roles, compared to those non-carers in full-time (FT) or part-time (PT) employment, were estimated using counterfactual simulation with Monte Carlo methods [30]. For each record of those NILF due to their caregiving roles, a counterfactual record was selected at random with replacement from the pool of noncarers who were in full-time employment, that is, this study quantifies theoretical maximum impact of the condition, the burden of disease. Records were matched for age group, sex, and highest level of education. The mean of the difference in these economic outcomes between the records of those NILF due to their caregiving roles 
and their counterfactuals was estimated. While some studies take the approach of estimating the value of care provided, in this study we focus on actual costs [6]. A total of 5,000 simulations were run, generating 5,000 counterfactual datasets for records of those NILF due to caregiving roles. In order to estimate the national impact, a counterfactual record was selected from the pool of non-carers who were working part-time, full-time or looking for work (unemployed). The average of the 5,000 simulations and the $95 \%$ confidence interval (CI), estimated using the percentile method, are reported in this study. Analyses were conducted using SAS, version 9.4 (SAS Institute, Cary, NC, USA). The use of the data was approved by the Australian Bureau of Statistics Microdata Review Panel.

\section{Results}

There were approximately 8,044 primary informal carers not in the labour force providing care for someone who lives with them with back pain, projected to increase to 10,069 in 2030 (25\% increase, Table 1). Within Australia's 2015 population of 23.9 million, $0.03 \%$ of the population were informal carers of people with back pain. The proportion of people who care for someone with back pain, as expected, was skewed towards women ( $68 \%$ of carers are women, $32 \%$ are men, Figure 2$)$.

The difference in weekly income, adjusted for age, gender and highest level of education, between full-time employed non-carers and those not in the labour force due to caring for people with back pain was an average of $\$ 890$ in 2015 , increasing to $\$ 1,079$ in 2030 , a $21 \%$ increase (Table 2). The average difference in weekly income between those non-carers employed part-time and those not in the labour force due to informal caring was \$294 in 2015, rising to \$363 in 2030, a 25\% increase (Table 2). The average difference in tax payments between full-time carers and those not in labour force due to caring for people with back pain was $\$ 265$ in 2015, increasing to $\$ 318$ in 2030, a 19\% increase (Table 2). The difference between estimates in Table 1 (mean values of individual costs) and Table 2 are because Table 1 contains the raw mean values and Table 2 shows the differences after adjusting for age, gender and highest level of education. In addition, not all 8,400 carers would be working full or part time, some would be unemployed. Values in Table 3 account for those informal carers who would return to being unemployed if they stopped being carers. This is why the number in Table 3 is lower than expected if multiplying weekly averages by 52 . 
The total loss of income due to caring increased substantially from $\$ 258$ million (95\% CI: $\$ 207$ - \$321 million) in 2015, rising to \$398 million (95\% CI: \$329 - \$483 million) in 2030 (54\% increase). Similarly, the total costs to government grew substantially. Total annual lost taxation revenue to the Australian Government due to lost labour force because of informal caring was estimated to be AU\$78 million in 2015 (95\% CI: \$61 - \$103 million), increasing to AU\$118 million (95\% CI: \$93 - \$151 million) in 2030, also an increase of $54 \%$. Similarly, the total annual additional welfare payments due to informal carers being out of the labour force was estimated at AU\$132 million (95\% CI: \$140 - \$124 million) increasing to AU \$180 million in 2030 (95\% CI: \$170 - \$189), an increase of $37 \%$ (Table 3). The Australian government provides a Carers Allowance, and Carers Payment, as well as rent assistance and family payments, meaning informal carers who are not employed may have a non-zero income.

\section{Discussion:}

The motivation behind this study was to estimate the impact of informal caring of back pain for Australians aged 15-64, projected to future years (2015 to 2030). Modelling conducted in this study estimated that carers of people with back pain received only $35 \%$ of the median weekly income of full-time employed non-carers in 2015 (\$445 versus $\$ 1,280$; Table 1). By 2030, carers of people with back pain were projected to receive only $33 \%$ of the median income of full-time non-carers ( $\$ 495$ versus $\$ 1502$ ). The median total weekly welfare payments were $\$ 360$ for carers, increasing to $\$ 394$ in 2030 (9.4\% increase). As expected, the median welfare payment for full-time employed non-carers was $\$ 0$. It is important to note that growth in lost income, compared to the relatively smaller increase in welfare payments, means that the income gap between carers and those in the workforce, is likely to widen leading to compounding inequality between informal carers and non-carers.

\section{Economic impacts of back pain}

Previous international studies have estimated that in aggregate, because back pain is a common condition, it is also very costly [16], and costs are increasing [13; 33]. A number of studies have estimated productivity losses due to chronic back pain, using a variety of methods $[10 ; 14 ; 16 ; 18 ; 19]$, however, few studies have estimated costs of informal care for back pain. A review of the costs of low back pain [10] estimated a 
range of national level indirect costs from $\$ 7,400$ million in a study from 2004 [20] to $\$ 28,170$ million in the USA, in a 1996 study [21]. Studies on back pain in Australia have estimated lost productivity, savings, and reduced wealth [26; 34]. However, these studies described the impact of back pain on patients, here we provide estimates of the costs due to informal caring. The indirect costs of back pain for all Australians aged 45 to 64 years old, who retire early because of it, were estimated at a total income loss of $\$ 2,931$ million per year in 2015 which was estimated to increase to a total income loss of $\$ 4,660$ million per year in 2030 [25]. If we add the indirect costs of Australian informal carers, who stay out of the workforce to provide care for those with back pain, the total estimated indirect costs of back pain will approximately increase by $8.5 \%$ to about $\$ 5,058$ million per year in 2030 .

\section{Informal carers and back pain}

The few previous studies on informal caring for people with back pain have also reported large economic impacts, yet are decades old and used different methods. One UK study on the cost-of-illness of back pain from 1994 estimated that informal care had a total cost of $£ 1.56$ billion, although this study used different methodology and was conducted decades earlier [16]. This UK estimate assumed one hourly rate of pay for each informal carer, and multiplied this by the estimated hours out of the workforce due to caring. In contrast, we used survey data to capture individuals who were out of the workforce due to informal care of back pain, and then modelled the lost income of informal carers matching incomes based on the carers specific age, gender and education level. A recent Australian study estimated economic impacts for informal carers of all conditions and resultant lost productivity, but this study reported on many chronic conditions, not exclusively back pain [28]. Informal care of people with back pain leads to not only reduced workplace productivity, but also physical impacts, isolation and reduced mental health $[22 ; 31]$. Additionally, it is noteworthy that the back pain of the carer can be aggravated, or caused, by the act of caring [23].

The impact of a disability such as back pain on work force productivity is likely to increase with age. The results from this study confirm the conclusion of previous studies, that informal care for a person with a chronic condition can lead to reduced employment and income [24; 28]. Similarly, a larger proportion of informal carers of people with back pain are women than men. This is true in the present study and for all 
chronic conditions [28]. Given a large proportion of women are reported to retire with little personal savings and reduced superannuation due to broken careers, compared with men [9], this leads to greater disparity in wealth between men and women, as well as between carers and non-carers. Interventions for back pain and their carers would be beneficial for preventing increasing income inequality and compounding disadvantage.

\section{Limitations}

This study has several limitations. First, the data in the Survey of Disability Ageing and Carers (SDAC) survey are self-reported by carers. Nevertheless, this is a commonly used method, particularly for workforce participation studies [28], and previous papers recognized this approach as reliable [32]. One study that compared the self-reported health measures with other objective health measures for their relationship with workforce participation reported that self-reported data were no less reliable than objective measures [3]. Further, most informal carers were providing more than 20 hours of care per week, and thus would be unlikely to be able to work given these time limitations.

Second, this study does not report on the non-economic costs of back pain. Caring has an impact on the carer's health and wellbeing as well as a societal impact through the absence of work force participation [12]. Also, survey data is taken from a subset of the population, although the dataset has been weighted by age, gender and education level to reflect the general Australian population. Our study was limited to ages 15 to 64 years, only cared for people in the same household, and only captures the formal economy, not lost leisure time. Being a carer can also increase the risk of their own back pain [23], yet these impacts are beyond the scope of this study which focuses on informal carers. Further, while back pain may not be the sole chronic condition in many recipients of care, in the survey, respondents identified back pain as their main chronic condition. We have only included the impact on carers where back pain was reported as the main condition of the person being cared for. Carers of persons reporting chronic pain as a co-morbidity were not included in this analysis.

\section{Implications: future directions and policies.}

Although economic impacts of back pain are known, the impact of provision of care and services for carers has rarely been quantified. Policies that prevent or provide more 
effective treatment for back pain, or, for example, make it possible for patients with back pain to return to the work force, will also improve the informal carers mental health and quality of life $[4 ; 7]$. Policies to improve productivity of carers may include improved interventions or treatments to prevent long-term back pain, increased awareness of informal carers rights to leave provisions and flexible working arrangements, and improved access to replacement care and respite services [5]. The increase in an ageing population, both in absolute numbers and as a proportion of the overall population means that in future, interventions and policies addressing back pain will be even more important than at present.

Back pain is a common condition and increasing in both numbers and the proportion of total population, meaning policies which address back pain have the potential to improve the well-being of increasing numbers of people. One review on the epidemiological and economic burden of back pain in France, Germany, Italy, Spain and the UK reported prevalence estimates for chronic low back pain of 5.9\% for Italy and $6.3-11.1 \%$ for the UK [14]. This high prevalence, from $5.9 \%$ to $11.1 \%$ has significant impacts on capacity to work and care requirements, and thus policies addressing informal care of people with back pain may play a significant role in increasing the productivity of a country. Thus, early treatment and intervention of back pain may mean that a proportion of carers could return to the workforce. The resultant increased taxation revenue and decreased welfare would be one step towards offsetting health costs of an ageing population, as suggested by the Intergenerational Report [8].

Economic modelling can be used to see the effects of different interventions and types of health care for patients with low back pain, and to influence these pathways to increase quality of life for patients, and their carers [29]. By investing in strategies to prevent and treat back pain, and allow informal carers to return to work, this may lead to associated increased mental, physical health and economic benefits for both carers and people with back pain. Quantifying economic impacts of caring is important as back pain is one of the most common conditions [33], its prevalence is increasing with an ageing population, and indirect costs are amongst the highest costs of conditions studied [16].

\section{Conclusion}


Back pain is a major problem globally and an ageing population means that informal care requirements for people with back pain will increase in future. Informal carers staying out of the work force to provide care for people with back pain lead to a large and rising economic burden in future. Policies addressing prevention and treatment of back pain, and support for informal carers returning to the workforce are crucial as global populations age and health resources become increasingly scarce, to prevent the widening gap between carers and non-carers. 


\section{Acknowledgements and Funding sources}

This study is part of continuing research funded by a National Health and Medical Research Council (NHMRC) Partnership Project (APP 1055037) with Pfizer Australia and Carers Australia as partner organisations. All authors are independent from the funding sources, and the funding sources (including Pfizer Australia) played no part in the research design, undertaking of the analysis, formulation or interpretation of the results, decision to publish the research findings, nor any other part of the research process. MP is funded by fellowships from the National Health and Medical Research Council, and the Sydney Medical School Foundation.

\section{Conflict of Interest Statement}

We are financially independent of the funding sources, and the funding sources (including Carers Australian and Pfizer Australia) played no part in the research design, the analysis, formulation or interpretation of the results, the decision to publish the research findings, or in any other aspect of the research process.

\section{Tables and Figures}

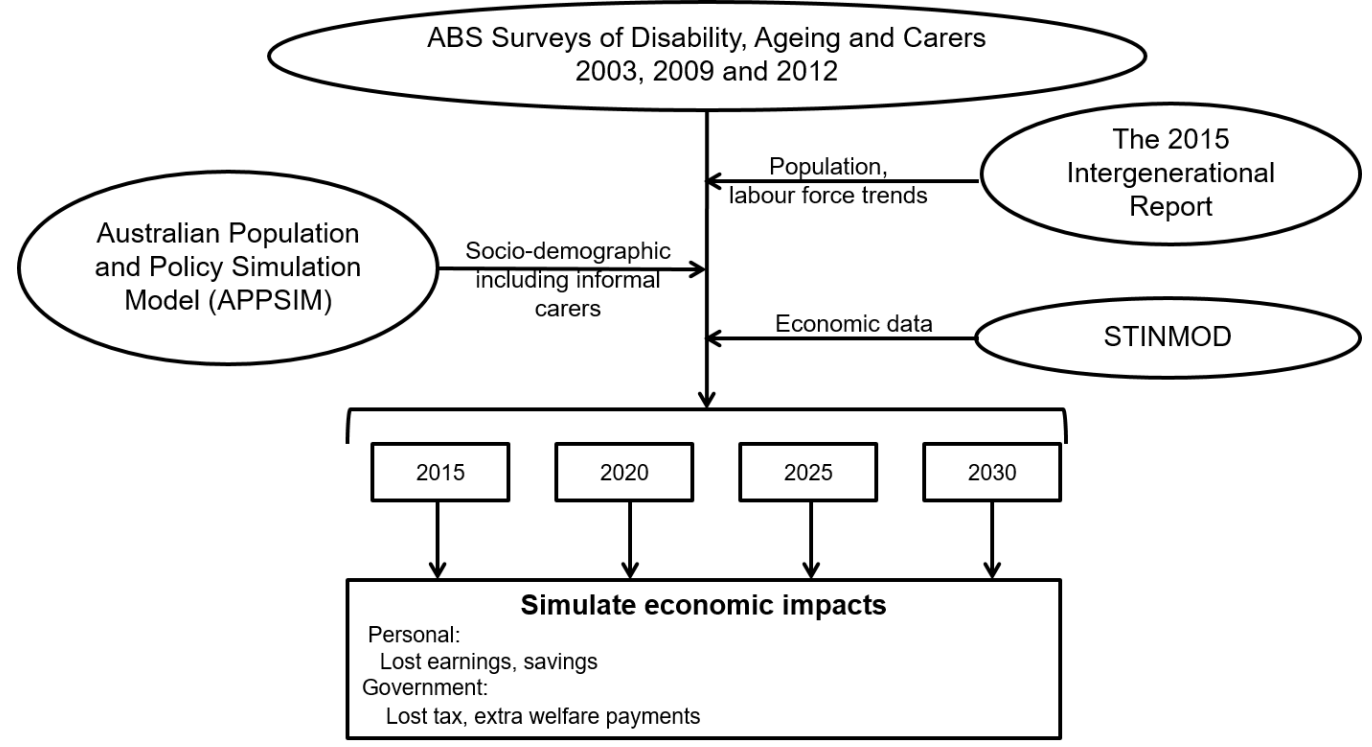

Figure 1. Inputs and output models and data comprising Care\&WorkMOD, including data from the Surveys of Disability, Ageing and Carers, as well as models APPSIM, providing socio-demographic trends, and STINMOD, providing economic data, combined with the 2015 Intergenerational Report, providing labour force trends. 


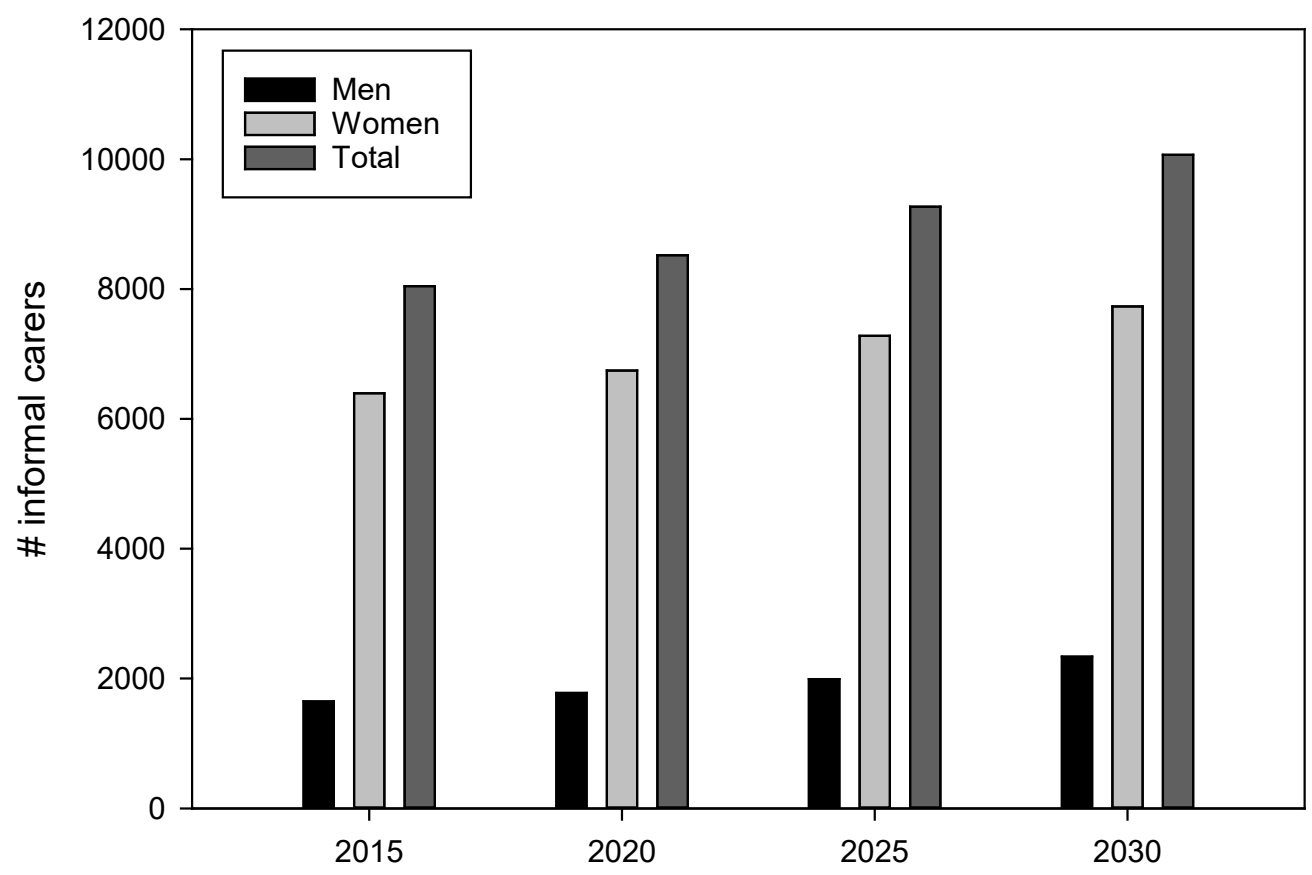

Figure 2. People not in the labour force due to providing informal carers of back pain, by gender, of 37186 Australians aged 15-64 years surveyed in 2015, projected to 2030. Numbers represent the primary carers of the usual resident (i.e. they live with) care recipients, and are weighted by age, gender and education level to represent the total Australian population. 
Table 1: Average and median weekly total income, welfare payments and taxes paid by individuals, Australian population aged 15-64 years, (in 2015 \$). Data show estimates for non-carers employed full-time, non-carers employed part-time, and those not in the labour force due to informal caring responsibilities.

\begin{tabular}{|c|c|c|c|c|c|c|c|c|c|c|c|c|c|c|c|c|c|}
\hline \multirow[b]{2}{*}{ Labour force status } & \multirow{2}{*}{$\begin{array}{l}\mathrm{N} \\
\text { Survey } \\
\text { records }\end{array}$} & \multicolumn{4}{|l|}{2015} & \multicolumn{4}{|l|}{2020} & \multicolumn{4}{|l|}{2025} & \multicolumn{4}{|l|}{2030} \\
\hline & & $\begin{array}{l}\text { Weighte } \\
\text { d pop. }\end{array}$ & Mean & SD & Median & $\begin{array}{l}\text { Weighted } \\
\text { pop. }\end{array}$ & Mean & SD & Median & $\begin{array}{l}\text { Weighted } \\
\text { pop. }\end{array}$ & Mean & SD & Median & $\begin{array}{l}\text { Weighted } \\
\text { pop. }\end{array}$ & Mean & SD & Median \\
\hline \multicolumn{18}{|c|}{ Weekly total income (\$) of individuals } \\
\hline $\begin{array}{ll}\begin{array}{l}\text { Employed } \\
\text { non-carers }\end{array} & \text { full-time, } \\
\end{array}$ & 51,455 & $\begin{array}{c}7,362,00 \\
0 \\
\end{array}$ & 1544 & 1,611 & 1,280 & $8,002,000$ & 1,625 & 1,677 & 1,340 & 8549,000 & 1,727 & 1,773 & $\begin{array}{c}1,41 \\
0\end{array}$ & $9,028,000$ & 1854 & 1820 & 1502 \\
\hline $\begin{array}{l}\text { Employed part-time, } \\
\text { non-carers }\end{array}$ & 22,120 & $\begin{array}{c}3,116,00 \\
0 \\
\end{array}$ & 647 & 83 & 488 & $3,158,000$ & 714 & 915 & 550 & 3390,000 & 752 & 976 & 576 & $3,592,000$ & 799 & 1041 & 623 \\
\hline $\begin{array}{l}\text { Not in the labour force } \\
\text { due to informal caring }\end{array}$ & 78 & 8,044 & 425 & 168 & 445 & 8,521 & 432 & 181 & 458 & 9,269 & 453 & 184 & 477 & 10,069 & 474 & 184 & 495 \\
\hline \multicolumn{18}{|c|}{ Total weekly welfare payments (\$) } \\
\hline $\begin{array}{ll}\begin{array}{l}\text { Employed } \\
\text { non-carers }\end{array} & \text { full-time, } \\
\end{array}$ & 51,455 & $\begin{array}{c}7,362,00 \\
0 \\
\end{array}$ & 26 & 81 & 0 & $8,002,000$ & 26 & 80 & 0 & 8549,000 & 27 & 83 & 0 & $9,028,000$ & 27 & 83 & 0 \\
\hline $\begin{array}{l}\text { Employed part-time, } \\
\text { non-carers }\end{array}$ & 22,120 & $\begin{array}{c}3,116,00 \\
0 \\
\end{array}$ & 80 & 142 & 6 & $3,158,000$ & 81 & 142 & 6 & 3390,000 & 81 & 142 & 6 & $3,592,000$ & 81 & 143 & 6 \\
\hline $\begin{array}{l}\text { Not in the labour force } \\
\text { due to informal caring }\end{array}$ & 78 & 8,044 & 332 & 219 & 360 & 8,521 & 333 & 223 & 347 & 9,269 & 347 & 225 & 365 & 10,069 & 363 & 228 & 394 \\
\hline \multicolumn{18}{|c|}{ Total weekly tax payments $(\$)$} \\
\hline $\begin{array}{ll}\begin{array}{l}\text { Employed } \\
\text { non-carers }\end{array} & \text { full-time, } \\
\end{array}$ & 51,455 & $\begin{array}{c}7,362,00 \\
0 \\
\end{array}$ & 357 & 519 & 254 & $8,002,000$ & 378 & 557 & 265 & 8549,000 & 405 & 601 & 280 & $9,028,000$ & 439 & 641 & 302 \\
\hline $\begin{array}{l}\text { Employed part-time, } \\
\text { non-carers }\end{array}$ & 22,120 & $\begin{array}{c}3,116,00 \\
0\end{array}$ & 72 & 287 & 4 & $3,158,000$ & 83 & 315 & 10 & 3390,000 & 87 & 338 & 11 & $3,592,000$ & 94 & 361 & 16 \\
\hline $\begin{array}{l}\text { Not in the labour force } \\
\text { due to informal caring }\end{array}$ & 78 & 8,044 & 1 & 8 & 0 & 8,521 & 0 & 12 & 0 & 9,269 & 0.7 & 12 & 0 & 10,069 & 1 & 12 & 0 \\
\hline
\end{tabular}


Table 2: Differences in mean weekly income (adjusted for age, sex and education) by labour force and carer status, Australian population aged $15-64$ years, (in 2015 ). Estimates are not directly calculated from Table 1 as Table 2 values have also been adjusted for age, sex and education.

\begin{tabular}{|c|c|c|c|c|c|c|c|c|}
\hline & \multicolumn{2}{|l|}{2015} & \multicolumn{2}{|l|}{2020} & \multicolumn{2}{|l|}{2025} & \multicolumn{2}{|l|}{2030} \\
\hline Labour force and carer status & \$ difference & $95 \% \mathrm{CI}$ & \$ difference & $95 \% \mathrm{CI}$ & \$ difference & $95 \% \mathrm{CI}$ & \$ difference & $95 \% \mathrm{CI}$ \\
\hline \multicolumn{9}{|c|}{ Weekly total income (\$) of individuals } \\
\hline $\begin{array}{l}\text { Difference between employed full-time } \\
\text { non-carers and those not in the labour force } \\
\text { due to informal caring }\end{array}$ & 890 & $(769 ; 1048)$ & 933 & $(809 ; 1091)$ & 1002 & $(870 ; 1167)$ & 1079 & $(944 ; 1256)$ \\
\hline $\begin{array}{l}\text { Difference between employed part-time } \\
\text { non-carers and those not in the labour force } \\
\text { due to informal caring }\end{array}$ & 294 & $(206 ; 407)$ & 316 & $(228 ; 438)$ & 336 & $(250 ; 447)$ & 363 & $(274 ; 471)$ \\
\hline \multicolumn{9}{|c|}{ Total weekly welfare payments (\$) received by individuals } \\
\hline $\begin{array}{l}\text { Difference between employed full-time } \\
\text { non-carers and those not in the labour force } \\
\text { due to informal caring }\end{array}$ & -352 & $(-365 ;-337)$ & -355 & $(-369 ;-340)$ & -368 & $(-382 ;-354)$ & -384 & $(-397 ;-371)$ \\
\hline $\begin{array}{l}\text { Difference between employed part-time } \\
\text { non-carers and those not in the labour force } \\
\text { due to informal caring }\end{array}$ & -302 & $(-323 ;-278)$ & -304 & $(-325 ;-282)$ & -317 & $(-338 ;-295)$ & -332 & $(-352 ;-311)$ \\
\hline \multicolumn{9}{|c|}{ Total weekly tax payments (\$) } \\
\hline $\begin{array}{l}\text { Difference between employed full-time } \\
\text { non-carers and those not in the labour force } \\
\text { due to informal caring }\end{array}$ & 265 & $(221 ; 332)$ & 272 & $(228 ; 335)$ & 293 & $(246 ; 359)$ & 318 & $(266 ; 386)$ \\
\hline $\begin{array}{l}\text { Difference between employed part-time } \\
\text { non-carers and those not in the labour force } \\
\text { due to informal caring }\end{array}$ & 84 & $(58 ; 125)$ & 86 & $(61 ; 126)$ & 91 & $(66 ; 126)$ & 95 & $(71 ; 129)$ \\
\hline
\end{tabular}


Table 3: National lost income, tax and increased welfare payments due to primary carers of people with back pain not being in the labour force, Australians 15-64 years old, with 95\% confidence intervals (in 2015 \$ millions).

\begin{tabular}{|l|c|c|c|c|c|c|c|c|}
\hline & \multicolumn{2}{|c|}{2015} & \multicolumn{2}{c|}{2020} & \multicolumn{2}{c|}{2025} & \multicolumn{2}{c|}{2030} \\
\hline \multicolumn{1}{|c|}{ Cost } & \$ million & $95 \%$ CI & \$ million & $95 \%$ CI & \$ million & $95 \%$ CI & \$ million & $95 \%$ CI \\
\hline $\begin{array}{l}\text { Individuals: Lost } \\
\text { income }\end{array}$ & 258 & $(207 ; 321)$ & 288 & $(233 ; 357)$ & 340 & $(277 ; 415)$ & 398 & $(329 ; 483)$ \\
\hline $\begin{array}{l}\text { Government: Lost } \\
\text { tax payments }\end{array}$ & 78 & $(61 ; 103)$ & 85 & $(67 ; 113)$ & 101 & $(79,129)$ & 118 & $(93 ; 151)$ \\
\hline $\begin{array}{l}\text { Government: } \\
\text { Increased welfare } \\
\text { payments }\end{array}$ & 132 & $(140 ; 124)$ & 140 & $(148 ; 131)$ & 158 & $(167 ; 149)$ & 180 & $(189 ; 170)$ \\
\hline
\end{tabular}




\section{References}

[1] Australian Bureau of Statistics. Information Paper - Basic Confidentialised Unit Record File: Survey of Disability, Ageing and Carers 2003 (reissue). Canberra: Australian Bureau of Statistics, 2005.

[2] Australian Bureau of Statistics. Survey of Disability, Ageing and Carers 2009 Vol. Cat. No. 4430.0. Canberra: Australian Bureau of Statistics, 2012.

[3] Bound J. Self-Reported Versus Objective Measures of Health in Retirement Models. The Journal of Human Resources 1991;26(1):106-138.

[4] Buchbinder R, van Tulder M, Öberg B, Costa LM, Woolf A, Schoene M, Croft P, Buchbinder R, Hartvigsen J, Cherkin D, Foster NE, Maher CG, Underwood M, van Tulder M, Anema JR, Chou R, Cohen SP, Menezes Costa L, Croft P, Ferreira M, Ferreira PH, Fritz JM, Genevay S, Gross DP, Hancock MJ, Hoy D, Karppinen J, Koes BW, Kongsted A, Louw Q, Öberg B, Peul WC, Pransky G, Schoene M, Sieper J, Smeets RJ, Turner JA, Woolf A, Lancet Low Back Pain Series Working G. Low back pain: a call for action. The Lancet 2018.

[5] Carers NSW. Carers NSW 2018 Carer Survey: Summary report., 2018.

[6] Casey B. The Value and Costs of Informal care. Institute for Employment Research, Warwick: University of Warwick, 2011.

[7] Clark S, Horton R. Low back pain: a major global challenge. The Lancet 2018;391(10137):2302.

[8] Commonwealth of Australia. 2015 Intergenerational Report: Australia in 2055. Canberra: The Commonwealth of Australia, 2015.

[9] Craft A, S. Taylor, Gaffney A, Wagland S. Retirement outcomes for female primary carers in Australia: A literature review. Financial Planning Research Journal 2018;4(2):70-93.

[10] Dagenais S, Caro J, Haldeman S. A systematic review of low back pain cost of illness studies in the United States and internationally. Spine Journal 2008;8(1):8-20.

[11] Hartvigsen J, Hancock MJ, Kongsted A, Louw Q, Ferreira ML, Genevay S, Hoy D, Karppinen J, Pransky G, Sieper J, Smeets RJ, Underwood M, Buchbinder R, Hartvigsen J, Cherkin D, Foster NE, Maher CG, Underwood M, van Tulder M, Anema JR, Chou R, Cohen SP, Menezes Costa L, Croft P, Ferreira M, Ferreira PH, Fritz JM, Genevay S, Gross DP, Hancock MJ, Hoy D, Karppinen J, Koes BW, Kongsted A, Louw Q, Öberg B, Peul WC, Pransky G, Schoene M, Sieper J, Smeets RJ, Turner JA, Woolf A, Lancet Low Back Pain Series Working G. What low back pain is and why we need to pay attention. The Lancet 2018.

[12] Hoefman RJ, van Exel J, Brouwer W. How to Include Informal Care in Economic Evaluations. PharmacoEconomics 2013;31(12):1105-1119.

[13] Hong J, Reed C, Novick D, Happich M. Costs associated with treatment of chronic low back pain: An analysis of the UK general practice research database. Spine 2013;38(1):75-82.

[14] Juniper M, Le TK, Mladsi D. The epidemiology, economic burden, and pharmacological treatment of chronic low back pain in France, Germany, Italy, Spain and the UK: A literature-based review. Expert Opinion on Pharmacotherapy 2009;10(16):2581-2592.

[15] Keegan M, Kelly S. APPSIM - Dynamic microsimulation modelling of social security and taxation. Canberra: National Centre for Social and Economic Modelling, University of Canberra, 2009. 
[16] Maniadakis N, Gray A. The economic burden of back pain in the UK. Pain 2000;84(1):95-103.

[17] Nguyen HT, Connelly LB. The effect of unpaid caregiving intensity on labour force participation: Results from a multinomial endogenous treatment model. Social Science and Medicine 2014;100:115-122.

[18] Olafsson G, Jonsson E, Fritzell P, Hägg O, Borgström F. A health economic lifetime treatment pathway model for low back pain in Sweden. Journal of Medical Economics 2017;20(12):1281-1289.

[19] Percival R, Abello A, Vu Q. STINMOD (Static Income Model). In: Gupta A, Harding A, editors. Modelling Our Future: Population ageing, health and aged care. Amsterdam: Elsevier B.V., 2007.

[20] Ricci JA, Stewart WF, Chee E, Leotta C, Foley K, Hochberg MC. Back pain exacerbations and lost productive time costs in United States workers. Spine (Phila Pa 1976) 2006;31(26):3052-3060.

[21] Rizzo JA, Abbott TA, 3rd, Berger ML. The labor productivity effects of chronic backache in the United States. Medical care 1998;36(10):1471-1488.

[22] Roca RM, Ubeda BI, Fuentelsa GC, Lópe zPR, Pont RA, García VL, Pedreny OR. Impact of caregiving on the health of family caregivers. Aten Primaria 2000;26(4):217-223.

[23] Salvador-Piedrafita M, Malmusi D, Borrell C. Time trends in health inequalities due to care in the context of the Spanish Dependency Law. Gaceta Sanitaria 2017;31(1):11-17.

[24] Schofield D, Cunich M, Shrestha R, Passey M, Kelly S, Tanton R, Veerman L. The impact of chronic conditions of care recipients on the labour force participation of informal carers in Australia: Which conditions are associated with higher rates of non-participation in the labour force? BMC Public Health 2014;14(1).

[25] Schofield D, Cunich MM, Shrestha RN, Tanton R, Veerman L, Kelly SJ, Passey ME. The indirect costs of back problems (dorsopathies) in Australians aged 45 to 64 years from 2015 to 2030: results from a microsimulation model, Health\&WealthMOD2030. Pain 2016;157(12):2816-2825.

[26] Schofield D, Kelly S, Shrestha R, Callander E, Passey M, Percival R. The impact of back problems on retirement wealth. Pain 2012;153(1):203-210.

[27] Schofield D, Shrestha RN, Percival R, Kelly SJ, Passey ME, Callander EJ. Quantifying the effect of early retirement on the wealth of individuals with depression or other mental illness. The British journal of psychiatry : the journal of mental science 2011;198(2):123-128.

[28] Schofield D, Shrestha RN, Zeppel MJB, Cunich MM, Tanton R, Veerman JL, Kelly SJ, Passey ME. Economic costs of informal care for people with chronic diseases in the community: Lost income, extra welfare payments, and reduced taxes in Australia in 2015-2030. Health and Social Care in the Community 2019;27(2):493-501.

[29] Schofield D, Zeppel M, Tan O, Lymer S, Cunich MM, Shrestha RN. A Brief, Global History of Microsimulation Models in Health: Past Applications, Lessons Learned and Future Directions. International Journal of Microsimulation 2018;11(1):97-142.

[30] Schofield DJ, Shrestha RN, Cunich M, Tanton R, Kelly S, Passey ME, Veerman LJ. Lost productive life years caused by chronic conditions in Australians aged 45-64 years, 2010-2030. The Medical journal of Australia 2015;203(6):260.e261-266. 
[31] Shiue I. Assessing quality of life in Welsh carers with and without back pain. British Journal of Community Nursing 2015;20(7):338-343.

[32] Shrestha RN, Schofield D, Zeppel MJB, Cunich MM, Tanton R, Kelly SJ, Veerman L, Passey ME. Care\&WorkMOD: An Australian Microsimulation Model Projecting the Economic Impacts of Early Retirement in Informal Carers. International Journal of Microsimulation 2018;11(3):78-99.

[33] Vos T, Abajobir AA, Abbafati C, et al. Global, regional, and national incidence, prevalence, and years lived with disability for 328 diseases and injuries for 195 countries, 1990-2016: A systematic analysis for the Global Burden of Disease Study 2016. The Lancet 2017;390(10100):1211-1259.

[34] Walker BF, Muller R, WD G. Low back pain in Australian adults: the economic burden. Asia Pac J Public Health 2003;15(2):79-87. 